\title{
First Year Experience in Assisted Reproductive Technology (ART) Services at IIUM Kuantan
}

\author{
Ahmad Murad Za, Roszaman Ra, Azantee YWa, Hayati MYa, Norsina $M A^{b}$, Siti $K^{\mathrm{a}}$ \\ aIIUM fertility centre, International Islamic University Malaysia (IIUM), Kuantan, Pahang, Malaysia. \\ ${ }^{b}$ Department of O\&G, Kulliyyah of Medicine, IIUM, Kuantan, Pahang, Malaysia.
}

\begin{abstract}
Introduction: To analyze the ART outcome and factors associated with successful ART treatment for infertile couples in a newly set up medical university IVF centre. Methods: A six-month cohort study of patients undergoing their first assisted reproductive technique cycle was conducted at IIUM fertility centre, Kuantan (from 15th June until 31st Dec 2009). Outcome measures include clinical pregnancy rate, ongoing pregnancy rate, take home baby rate and complications rate. Results: Fifty-five first cycles of IVF/ICSI were studied. Mean embryo per transfer was $2.1 \pm 0.8$. Four patients were pregnant $(23.5 \%)$ from a single embryo transfer (SET). Clinical pregnancy rate was $30.9 \%(17 / 55)$. Ongoing pregnancy rate was $23.6 \%(13 / 55)$ and take home baby rate was $21.8 \%(12 / 55)$. There was only one twin pregnancy. Nine patients $(16.4 \%)$ had OHSS whereby $77.8 \%$ were mild and $22.2 \%$ were moderate. Conclusion: Take home baby rate at the IIUM fertility centre is comparable to most established ART centres in Malaysia considering that this is only the first year of operation.
\end{abstract}

KEYWORDS: Assisted reproductive techniques, ovarian stimulation, outcomes assessment, embryo transfer, ovarian hyperstimulation syndrome

\section{INTRODUCTION}

The setting up of an assisted reproductive technology (ART) centre offering in-vitro fertilization (IVF) or intra-cytoplasmic sperm injection (ICSI) in the east coast region of Peninsular Malaysia has been long awaited. In 2006, a newspaper article highlighted that there were around 300,000 new couples seeking treatment in Malaysia ${ }^{1}$ (NST 28 Feb 2006, page 26). However, the claim is not based upon empirical data due to lack of studies, which have looked specifically into this matter in Malaysia. Nevertheless, since then five more government-funded fertility centers, apart from the two established in 1986 (LPPKN) and 1998 (HUKM), were set up. The centers were established at Hospital K Lumpur (2006), Hospital Alor Star (Mac 2009), IIUM Fertility Center (June 2009), Hospital Kuala Terengganu (November 2009) and Hospital Likas (July 2010). The setting up of IIUM Fertility Center was long-awaited since it was the first government-funded fertility center to have been opened for the public in the east coast region of Peninsular Malaysia. Interestingly there are more than 35 private centres in Malaysia that offer IVF services. ${ }^{2}$

Corresponding author:

Assoc. Prof. Dr Ahmad Murad Zainuddin IIUM Fertility Centre, International Islamic University Malaysia (IIUM), Kuantan, Pahang, Malaysia.

Phone: 006-0192689774

E-mail:dramz92@yahoo.com
The success rate of an ART treatment varies from centre to centre; ${ }^{3}$ it might be high for an established IVF centre but for a new centre, it would be challenging to achieve a reasonably good pregnancy outcome. The aim of this study was to analyze the ART treatment outcome and factors associated with successful ART treatment for infertile couples in a newly set up fertility centre.

\section{MATERIALS AND METHODS}

An observational prospective study involving 55 couples undergoing IVF/ICSI at an academic medical faculty in the east cost of Malaysia from $15^{\text {th }}$ June until 31 $1^{\text {st }}$ December 2009 was conducted. The first baby was delivered in March 2010, and last baby was delivered in August 2010.

Couples were offered short stimulation protocol, antagonist stimulation protocol or minimal stimulation after discussions on the advantages and disadvantages of the chosen stimulation protocol. Only the first cycle of IVF/ICSI was included in this study.

All couples are legally married. Complete infertility workout was done including sperm analysis, ovulation assessment and vaginal scan of female pelvic anatomy. Female tubal status was checked either via laparoscopy or hysterosalpingography. Donor sperm/oocyte is not allowed at our centre.

Ovarian pathology was determined by a vaginal scan. Polycystic ovarian syndrome was defined when there was a presence of a thickened capsule on vaginal scan, 
hirsutism/acne and/or high serum testosterone. Diagnosis of endometriosis was made based on laparoscopy finding and scored to the AFS guideline. ${ }^{4}$ Patients with severe endometriosis were excluded from the study. All patients had undergone intrauterine insemination two to six cycles before IVF/ ICSI. Sperm count of less than 5 million was defined as severe oligozoospermia ${ }^{5}$ and it was considered as male factor infertility.

In minimal stimulation protocol, the stimulation was started with either clomiphene citrate 100 to 150 $\mathrm{mg}$ daily or femara ${ }^{\circledR} 5 \mathrm{mg}$ daily from $2^{\text {nd }}$ to $6^{\text {th }}$ day of menses followed by recombinant FSH (Puregon ${ }^{\circledR}$ 50-150ii/ Gonal $F \circledast 75$ to 225ii) until leading follicles of 17-18 mm was observed. Ovulation was then triggered by human chorionic gonadotrophin (Ovidrel ${ }^{\circ} 6500$ ii). GnRH antagonist was not used in this stimulation protocol.

In the antagonist protocol group, recombinant $\mathrm{FSH}$ (Puregon $\AA 100$ to $300 \mathrm{IU} /$ Gonal $F \circledast 150$ to $300 \mathrm{IU}$ ) was used for ovulation induction starting on day two of menses until dominant follicles of $17-18 \mathrm{~mm}$ was achieved. Daily injection of Cetrotide ${ }^{\circledR} 0.25 \mathrm{mg} /$ Orgalutrone $^{\circledR}$ was started on day 6 of cycle (fixed regime) and continued up until the day of hCG injection (Ovidrel $® 6500$ IU).

In the short stimulation protocol group, recombinant FSH (Puregon $® 100$ to 300 IU/Gonal $F ® 150$ to 300IU) was used for ovulation induction starting on day two of menses until dominant follicles of $17-18 \mathrm{~mm}$ was achieved. hCG (Ovidrel ${ }^{\circledR} 6500 \mathrm{IU}$ ) injection was then given to induce ovulation. There was no prior down regulation of the pituitary-ovarian axis in all the above stimulation protocols.

Vaginal ultrasound began on day 6 and 10. Follicular size was measured in three perpendicular planes, and the mean value was recorded. Transvaginal ultrasound-guided oocytes retrieval (using Cook® or Vitrolife ${ }^{\circledR}$ aspiration needles) was performed 34-36 hours after hCG injection, under local anesthesia (lignocaine 2\%). Occasionally, the oocytes retrieval was done under sedation (midazolam $5 \mathrm{mg}$ and pethidine $50-100 \mathrm{mg}$ ).

Washed sperms from fresh ejaculates after 3-7 days abstinence were obtained in the morning of the oocytes retrieval by coitus interruptus or masturbation. The analysis was performed according to WHO criteria ${ }^{6}$ and sperms were prepared either by swim up or density gradient protocol.
IVF/ICSI was done in the conventional manner. ${ }^{7}$ Oocytes were incubated for 3-6 hours, and oocytes assessment was performed at the time of ICSI or IVF. ICSI was performed with a semi-automated micromanipulator (Research Instruments, UK). Only MII oocytes were injected with a single motile sperm in commercial PVP (Vitolife $®$, Sweden). ICSI was performed in oligozoospermic husband, and in those with less than five oocytes retrieved. Combined IVF/ ICSI was done if more than ten mature oocytes were recovered with normal sperm parameters.

Fertilization was observed 16-18 hours after ICSI or IVF, and fertilization rate was based upon the number of zygotes with two or more pronuclei over MII eggs. Selection of embryos for transfer was according to modified Veeck scoring. ${ }^{8}$ The Embryo transfer was done on day 2 or 3 after oocytes retrieval. The number of embryos transferred was according to American Society for Reproductive Medicine (ASRM) guideline 2009.9 The recommended clinical guideline in Malaysia is that no more than three eggs or embryos are to be transferred in any one cycle of IVF/ICSI. ${ }^{5}$

Oral or vaginal progesterone pessaries was used for luteal phase support together with s.c hCG 1000 IU on day 1, 4, 7,10, and 13 post embryo transfer. Clinical pregnancy is defined as the ultrasound visualization of intrauterine gestational sac and fetal heart activity at a minimum of five weeks after oocytes retrieval. Ongoing pregnancy rate is defined as viable pregnancy which has gone beyond 12 weeks. Take home baby is defined as pregnancy ending in a delivery of a live baby.

\section{Data analysis}

The demographic data was evaluated, and factors associated with pregnancy outcome were then performed using Chi-square statistic test. Differences were considered statistically significant when $p<0.05$.

\section{RESULTS}

Patient demographic data and indication are shown in Table 1. Polycystic ovarian syndrome (PCOS) was found to be the main cause of infertility in this study (32.7\%) followed by unexplained infertility (29.2\%) and mild to moderate endometriosis (21.8\%). Majority of the couples had primary infertility (96.4\%). 
Table 1: Socio-demographic and reproductive characteristic of patients

\begin{tabular}{|c|c|c|}
\hline Characteristics $(n=55)$ & Number (\%) & p value* \\
\hline \multicolumn{3}{|l|}{ Age (years) } \\
\hline$\leq 29$ & $15(27.3)$ & \\
\hline $30-34$ & $19(34.5)$ & \\
\hline $35-39$ & $17(30.9)$ & 0.045 \\
\hline$\geq 40$ & $4(7.3)$ & \\
\hline \multicolumn{3}{|l|}{ Type of infertility } \\
\hline Primary & $53(96.4)$ & NS \\
\hline Secondary & $2(3.6)$ & \\
\hline \multicolumn{3}{|l|}{ Duration of infertility } \\
\hline $1-5$ & $30(55.8)$ & 0.014 \\
\hline$>5$ & $25(44.2)$ & \\
\hline \multicolumn{3}{|l|}{ Ethnicity } \\
\hline Malay & $49(89.1)$ & \\
\hline Chinese & $4(7.3)$ & NS \\
\hline Indian & $2(3.6)$ & \\
\hline \multicolumn{3}{|l|}{ Aetiology factors } \\
\hline Ovarian /PCOs & $18(32.7)$ & NS \\
\hline Idiopathic & $16(29.2)$ & NS \\
\hline Endometriosis & $12(21.8)$ & NS \\
\hline Tubal & $2(3.6)$ & NS \\
\hline Male & $7(12.7)$ & NS \\
\hline Semen parameters & $(M e a n \pm S D)$ & \\
\hline Volume (ml) & $2.7 \pm 0.9$ & NS \\
\hline Count $\left(\times 10^{6} / \mathrm{ml}\right)$ & $89 \pm 60.3$ & NS \\
\hline Motile progression (\%) & $49.4 \pm 19.3$ & NS \\
\hline
\end{tabular}

NS: not significant, * Categorical and continuous variables were analyzed by Pearson Chi-Square

Twenty six patients underwent stimulation with short protocol without an antagonist whereas twenty patients were put on antagonist protocol. Nine patients preferred minimal stimulation protocol and the main reason for choosing this regime was because it reduces the overall financial burden (Table2). The mean numbers of oocytes retrieved were 6.8 and 6.5 in short protocol and antagonist group respectively.
In the minimal stimulation group, the mean number of oocytes recovered was 7.3 , which is higher than the short and antagonist group. There was no significant difference in the number and quality of oocytes in all three groups of stimulation protocol. The mean number of embryo transfer was 2.1. 
Table 2. Characteristics of ART cycle

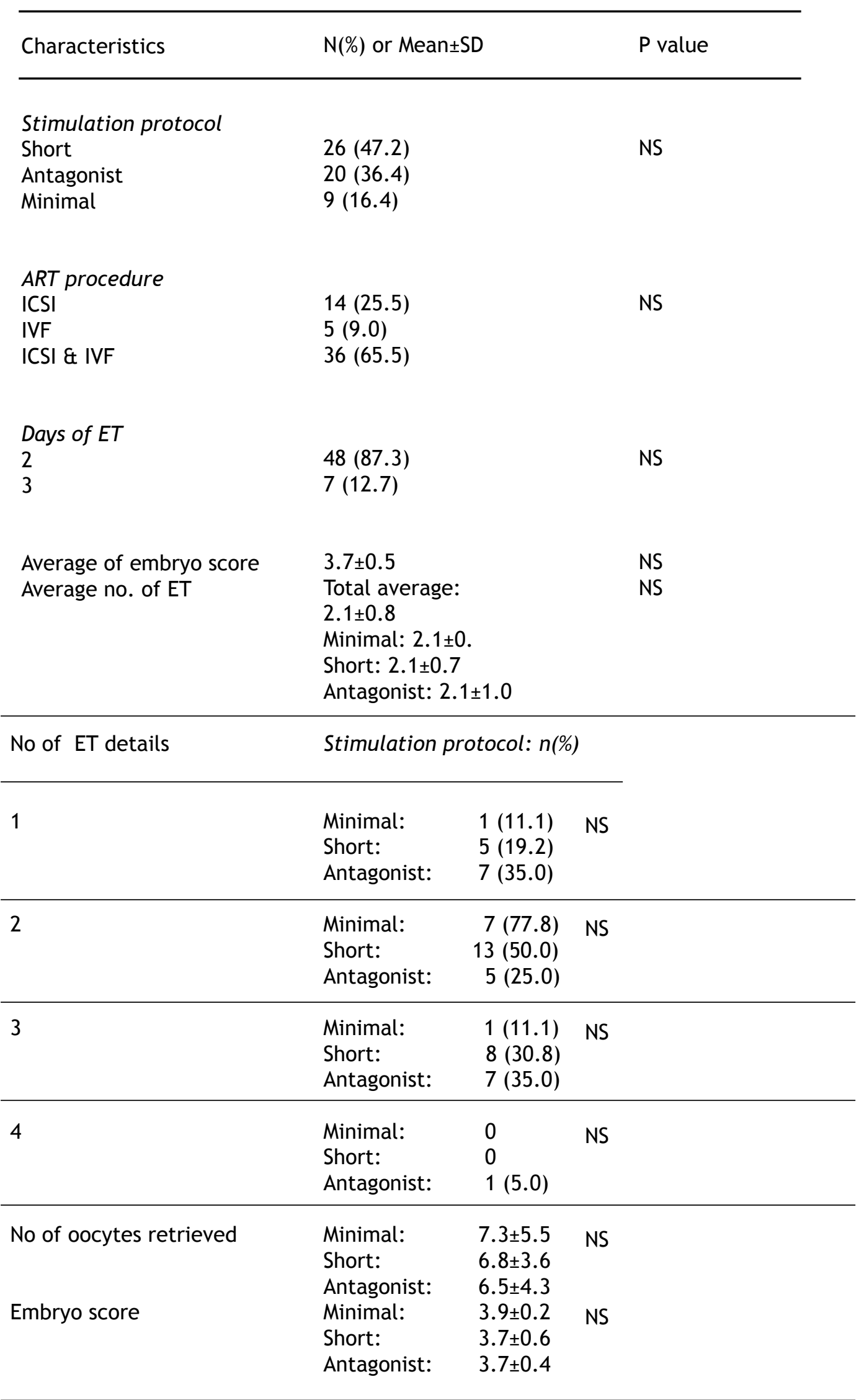

NS: Not significant, ET: Embryo transfer, ICSI: intra-cytoplasmic sperm injection, IVF: in-vitro fertilisation 
There were six and four babies delivered at term in short and antagonist group respectively, and two babies were delivered from the minimal stimulation group. The overall take home baby rate was 21.8 per embryo transfer, and all were singleton pregnancies. One couple who had a twin pregnancy ended up with miscarriages at the 14-week period of gestation.
There were three miscarriages $(17.6 \%)$ and there were one twin pregnancy and one ectopic pregnancy in the study (Table 3 ). The incidence of OHSS was $16.3 \%$ in which the majority was mild OHSS (77.8\%) (Table 4).

Table 3. ART outcome

\begin{tabular}{llllll}
\hline & \multicolumn{5}{c}{ Age category number $(\%)$} \\
\cline { 2 - 6 } Characteristics & $\begin{array}{l}\text { All category } \\
(\mathrm{n}=55)\end{array}$ & $\begin{array}{l}\leq 29 \text { years } \\
(\mathrm{n}=15)\end{array}$ & $\begin{array}{l}30-34 \text { years } \\
(\mathrm{n}=19)\end{array}$ & $\begin{array}{l}35-39 \text { years } \\
(\mathrm{n}=17)\end{array}$ & $\begin{array}{l}\geq 40 \text { years } \\
(\mathrm{n}=4)\end{array}$ \\
\hline Clinical pregnancy & $17(30.9)$ & $5(33.3)$ & $8(42.1)$ & $3(17.6)$ & $1(25.0)$ \\
Non-pregnant & $38(69.1)$ & $10(66.7)$ & $11(57.9)$ & $14(82.4)$ & $3(75.0)$ \\
$\begin{array}{l}\text { On-going pregnancy } \\
\text { Live birth }\end{array}$ & $13(23.6)$ & $5(33.3)$ & $6(31.5)$ & $2(11.7)$ & 0 \\
$\begin{array}{l}\text { Spontaneous miscarriage } \\
\text { Ectopic }\end{array}$ & $3(21.8)$ & $5(33.3)$ & $5(26.3)$ & $2(17.5)$ & 0 \\
& $1(5.9)$ & 0 & $1(5.2)$ & $1(5.8)$ & $1(25.0)$ \\
\hline
\end{tabular}

Table 4. Complications following ART

\begin{tabular}{ll}
\hline Complications & $\mathrm{N}(\%)$ \\
\hline Miscarriage & $3(17.6 \%)$ \\
Ectopic pregnancy & $1(5.9 \%)$ \\
Twin Pregnancy & $1(5.9 \%)$ \\
& \\
OHSS & $9(16.4 \%)$ \\
Mild & $7(77.8 \%)$ \\
Moderate & $2(22.2 \%)$ \\
Severe & 0
\end{tabular}

OHSS: ovarian hyperstimulation syndrome 


\section{DISCUSSION}

A proper set up of an ART unit is very crucial in ensuring a good outcome and most importantly, the take home baby rate. This study reports a $21.8 \%$ take home baby rate during the first 6 months of its services. A good centre would probably have a $30-40 \%$ of a take home pregnancy rate. ${ }^{3}$ This shows that even though the IIUM Fertility centre is still in its infancy, the take home pregnancy rate is comparable to other more established centers.

The overall clinical pregnancy rate (PR) was 30.9\% per started cycle. Women in the 30-34 years age group had the highest PR rate $(42.1 \%)$ and women in the $35-39$ years age group had the lowest PR (17.6\%) when a comparison is made based on the subject age group. The number of subjects was almost the same in the two age groups, whereas there were only four patients above 40 years old in this study. Therefore, the true PR for women above 40 years may not be accurate as the number of subjects was too small compared to the other three age groups.

Single embryo transfer (SET) does produce good results at our centre even though this is not a common practice in Malaysia. It has gained popularity, especially in Europe and in particular, for highquality embryos and favorable prognoses. ${ }^{10}$ SET helps to significantly reduce the incidence of multiple pregnancies, which should be considered as a complication in ART treatment. ${ }^{10}$ However, the live birth rate is still low if compared to double embryo (DET). ${ }^{10}$ It is not a routine practice at our centre to perform SET. It was done merely because that was the only embryo suitable for the transfer.

Transferring more than one embryo resulted in higher pregnancy rate. Half of the pregnancies were from DET, and all of these pregnancies ended up with singleton pregnancy. There was only one twin pregnancy following a DET. Only one patient had four embryos transferred and yet did not conceive.

OHSS remains one of the common complications as a result of ART, mainly due to the short protocol. This, however, is seen less in the antagonist and minimal stimulation cycle. ${ }^{11}$ Most of our patients were managed as an outpatient.

There is still a need to further reduce the incidence of moderate OHSS. $22.2 \%$ are rather high as compared to what has been suggested by the Royal College of Obstetrician \& Gynecologist UK. ${ }^{12}$ A strict written policy should be made available and the patients need to be carefully counseled regarding the possible worst outcome from OHSS.

\section{CONCLUSIONS}

Our success rate thus far has enabled patients from the east coast to be treated at this centre. This minimizes patients' cost of travelling and accommodation to get treatment in other regions throughout the country. Time off work can also be minimized, which allows patients to resume their daily routine soon after treatment. However, there is still room for improvement.

Firstly, free exchange of medical information is important in modern medical practice, including for patients in Malaysia. For ART services in Malaysia, it is still difficult to get information on the success rate, especially those provided by government agencies thus preventing couples from getting proper information on ART services provided by these agencies. However, this information is widely advertised by the private sector, especially through the Internet. IIUM fertility centre should take proactive action to disseminate information about the centre, success rate and other relevant information for a patient to get a clear picture of ART.

In addition, sharing of expertise between the private sector and government-funded centers would also ensure Malaysia ART activities are at par with other world-renowned centers. This is still not a common practice in Malaysia. Only UKM medical centre provides such training in Malaysia up until today. Such initiatives would facilitate new centers like IIUM Fertility Centre to learn and improve even more in the future.

Finally, more studies on SET are needed to provide further indication for its practice. To date, SET is a common practice in The Europe and Malaysia should conduct further research to find out its suitability for Malaysian population.

\section{REFERENCES}

1. 300,000 couples suffer from infertility. The New Straits Times (Malaysia) 2006, February 28. Available at http://www. accessmylibrary.com/archive/434962-newstraits-times/february-2006.html

2. Obstetrical and Gynaecological Society of Malaysia (OGSM). Available at www.ogsm. org.my/the_subfertile_woman.php

3. Gunby J, Bissonnette F, Librach C, et al. Assisted reproductive technologies in Canada: 2005 results from Canadian Assisted Reproductive Technologies Register. Fertil Steril 2009; 91:1721-30.

4. American Fertility Society. Revised American Fertility Society classification of endometriosis. Fertil Steril 1985; 43:351-2.

5. Rashid MR, Ong FB, Omar MH, et al. GnRH Agonist and GnRH Antagonist in Intracytoplasmic Injection Cycles. Med J Malaysia 2008: 63:113-7.

6. World Health Organization. WHO laboratory manual for the examination of the human semen and sperm-cervical mucus interection. 4th ed. Cambridge University Press; 1999. 
7. Allahbadia G, Basuray R (eds). The art and science of assisted reproductive techniques (ART). London: Taylor and Francis, 2004.

8. Veeck LP. Preembryo grading and degree of cytoplasmic fragmentation. In: Veeck LP, ed. An atlas of human gametes and conceptuses: an illustrated reference for assisted reproductive technology. New York, USA; 1999:46-51.

9. The Practice Committee of the Society for Assisted Reproductive Technology and the Practice Committee of the American Society for Reproductive Medicine. Guidelines on number of embryos transferred. Fertil Steril 2009; 92:1518-19.

10. Baruffi RL, Mauri AL, Petersen CG, et al. Single-embryo transfer reduces clinical pregnancy rates and live births in fresh IVF and Intra cytoplasmic Sperm Injection (ICSI) cycles: a meta-analysis. Reprod Biol Endocrinol 2009; 7:36.

11. Noorashikin $M$, Ong FB, Omar $M H$, et al. Affordable ART for developing countries: a cost benefits comparison of low dose stimulation versus high dose $\mathrm{GnRH}$ antagonist protocol. J Assist Reprod Genet 2008; 25:297303.

12. The Management of Ovarian Hyperstimulation Syndrome. Green top guideline no 5 Royal College of Obstetricians and Gynaecologists. Published September, 2006. Available at http: / / www.rcog.org.uk/womens-health/ clinical-guidance/management-ovarianhyperstimulation-syndrome-green-top- 5 